\title{
Carbon nanotubes and xerogels as supports of well-dispersed Pt catalysts for environmental applications
}

\author{
H.T. Gomes ${ }^{\mathrm{a}, \mathrm{b}}$, P.V. Samant ${ }^{\mathrm{a}}$, Ph. Serp ${ }^{\mathrm{c}}$, Ph. Kalck ${ }^{\mathrm{c}}$, J.L. Figueiredo ${ }^{\mathrm{a}}$, J.L. Faria ${ }^{\mathrm{a}, *}$ \\ ${ }^{a}$ Laboratório de Catálise e Materiais/Departamento de Engenharia Química, Faculdade de Engenharia da Universidade do Porto, \\ Rua Dr. Roberto Frias, 4200-465 Porto, Portugal \\ ${ }^{\mathrm{b}}$ Departamento de Tecnologia Química, Escola Superior de Tecnologia e de Gestão do Instituto Politécnico de Bragança, \\ Campus de Santa Apolónia, 5300-857 Bragança, Portugal \\ ${ }^{\mathrm{c}}$ Laboratoire de Catalyse, Chimie Fine et Polymères-Ecole Nationale Supérieure d'Ingénieurs en Arts Chimiques Et Technologiques, \\ 118 route de Narbonne, 31077 Toulouse Cedex 04, France
}

Received 8 December 2003; received in revised form 25 April 2004; accepted 13 June 2004

Available online 7 August 2004

\begin{abstract}
Different types of carbon materials including multi-walled nanotubes (MWNT), carbon xerogels (CX) and activated carbon (AC) were used as supports to prepare platinum catalysts $(1 \% \mathrm{w} / \mathrm{w})$, which were tested in the treatment of aqueous aniline solutions by catalytic wet air oxidation (CWAO). The prepared materials and catalysts were characterized by several techniques (SEM/EDS, TEM, $\mathrm{N}_{2}$ adsorption, TPD and $\mathrm{H}_{2}$ chemisorption). All catalysts presented a very high activity for the removal of aniline and total organic carbon (TOC). Catalyst activity and selectivity toward $\mathrm{CO}_{2}$ formation were found to depend on the nature of the support and concentration of oxygen containing functional groups on the surface of the materials.
\end{abstract}

(C) 2004 Elsevier B.V. All rights reserved.

Keywords: Multi-walled carbon nanotubes (MWNT); Carbon xerogels; Activated carbon; Carbon supported catalysts; Catalytic wet air oxidation (CWAO); Aniline.

\section{Introduction}

Carbon materials are often used as support for preparing metal-based catalysts. Carbon occurs in many allotropic forms, which includes fullerenes [1,2] and carbon nanotubes [3-7]. The discovery of carbon nanotubes triggered an intense research activity concerning their preparation, characterization and applications [8]. Carbon nanotubes can be produced in two forms, single-walled nanotubes (SWNT) or multi-walled nanotubes (MWNT). As a result of their mechanical and electronic properties, exciting new breakthroughs in materials and engineering science are expected. Exploring their ability as support for production of efficient heterogeneous catalysts is one of the current objectives of research. Although some examples of this type of applica-

\footnotetext{
* Corresponding author. Tel.: +351 225081 645; fax: +351 225081449 .

E-mail address: jlfaria@fe.up.pt (J.L. Faria).
}

tion started to be referred [9-14], systematic studies comparing the performances of different forms of carbon as catalyst support are now required.

Other types of carbon materials with characteristic textural properties are the carbonized resorcinol/formaldehyde resins referred in the pioneering work on the synthesis of organic aerogels [15], normally designated by carbon aerogels and xerogels [16]. These materials have attracted an enormous attention, due to the possibility of fine-tuning their textural properties during the sol-gel method employed for their preparation.

Because morphology and size do play an important role in the dispersion of the metal phase [17], the present study aims at comparing the efficiency of different metal catalysts supported on carbon xerogel (CX), MWNT and activated carbon (AC) in an environmental application.

The treatment of aniline containing effluents by wet air oxidation (WAO) has been reported and aims at the total 


\begin{tabular}{|c|c|}
\hline \multicolumn{2}{|c|}{ Nomenclature } \\
\hline \multicolumn{2}{|c|}{ List of symbols } \\
\hline$[\mathrm{TOC}]_{0}$ & Initial TOC concentration $(\mathrm{g} / \mathrm{L})$ \\
\hline$[\mathrm{TOC}]_{\mathrm{A}}$ & $\begin{array}{l}\text { TOC concentration of oxidized aniline } \\
(\mathrm{g} / \mathrm{L})\end{array}$ \\
\hline [TOC] & TOC concentration at a given time $(\mathrm{g} / \mathrm{L})$ \\
\hline$[\mathrm{TOC}]_{\mathrm{CO}_{2}}$ & TOC concentration leaving as $\mathrm{CO}_{2}(\mathrm{~g} / \mathrm{L})$ \\
\hline$[\mathrm{A}]_{0}$ & Initial aniline concentration $(\mathrm{g} / \mathrm{L})$ \\
\hline$[\mathrm{A}]$ & $\begin{array}{l}\text { Aniline concentration at a given time } \\
(\mathrm{g} / \mathrm{L})\end{array}$ \\
\hline$X_{\mathrm{A}}$ & Aniline conversion \\
\hline$X_{\text {TOC }}$ & TOC conversion \\
\hline$S_{\mathrm{BET}}$ & BET surface area $\left(\mathrm{m}^{2} / \mathrm{g}\right)$ \\
\hline$V_{\mu}$ & Micropore volume $\left(\mathrm{cm}^{3} / \mathrm{g}\right)$ \\
\hline$S_{\text {non- } \mu}$ & Non-microporous surface area $\left(\mathrm{m}^{2} / \mathrm{g}\right)$ \\
\hline$D_{\mathrm{M}}$ & Metallic dispersion (\%) \\
\hline$d_{\mathrm{P}}$ & Pt particle diameter (nm) \\
\hline $\mathrm{CO}$ & CO released by TPD $(\mu \mathrm{mol} / \mathrm{g})$ \\
\hline $\mathrm{CO}_{2}$ & $\mathrm{CO}_{2}$ released by TPD $(\mu \mathrm{mol} / \mathrm{g})$ \\
\hline $\mathrm{CO} / \mathrm{CO}_{2}$ & $\begin{array}{l}\text { Ratio between } \mathrm{CO} \text { and } \mathrm{CO}_{2} \text { released by } \\
\text { TPD }\end{array}$ \\
\hline Total $\mathrm{O}_{2}$ & Total $\mathrm{O}_{2}$ released by TPD $(\mu \mathrm{mol} / \mathrm{g})$ \\
\hline$W$ & Platinum concentration $\left(\mathrm{g}_{\mathrm{Pt}} / \mathrm{L}\right)$ \\
\hline$k$ & Kinetic rate constant $\left(\mathrm{mol} \mathrm{L}^{-1} \min ^{-1}\right)$ \\
\hline$K$ & Aniline adsorption constant (L/mol) \\
\hline 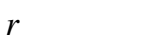 & Reaction rate $\left(\mathrm{mol} \mathrm{min}{ }^{-1} \mathrm{~g}_{\mathrm{Pt}}{ }^{-1}\right)$ \\
\hline & Initial reaction rate $\left(\mathrm{mol} \mathrm{min}{ }^{-1} \mathrm{~g}_{\mathrm{Pt}}{ }^{-1}\right)$ \\
\hline
\end{tabular}

oxidation of the organic species present in the effluent to $\mathrm{CO}_{2}, \mathrm{~N}_{2}$ and $\mathrm{H}_{2} \mathrm{O}$ under relatively severe conditions of temperature and pressure $\left(220-320^{\circ} \mathrm{C}, 50-200 \mathrm{bar}\right)$, using oxygen or air as oxidant [18-20]. Although very efficient, WAO involves high capital costs and costly safety measures, mainly due to materials corrosion, which requires the construction of large volume pressure reactors with special metal enriched alloys. This led to the development of catalysts capable of bringing the process conditions to more amenable values $\left(125-220^{\circ} \mathrm{C}, 5-50 \mathrm{bar}\right)$ in order to reduce energy consumption and the corresponding processing costs. Several catalysts were studied in the last decades. Initially, homogenous catalysts were found to be very efficient, but their use for wastewater treatment entails a further separation step in the process in order to remove them from the final treated effluent. On the other hand, heterogeneous catalysts can be easily removed by filtration and they will be the best choice if they are active, stable and selective to harmless end products. Effective systems are reported for oxidation of model compounds (phenol, carboxylic acids) [21-23]. In a previous work of our group, carbon supported platinum catalysts were found to present such desirable characteristics [24].

Among the existing treatment technologies, catalytic wet air oxidation (CWAO) is an efficient option for the treatment of aniline containing wastewaters. Aerobic biodegradation of aniline can be achieved only at very low concentrations (up to $350 \mathrm{mg} / \mathrm{L}$ ) without being toxic to nitrifying microorganisms [25]. Aniline is a key component in the production of polyurethane, it is used in the manufacture of dyes (including azo dyes) and intermediates for herbicides, other pesticides and rubber chemicals, such as vulcanization accelerators and antioxidants [26,27], thus being found in several types of wastewaters, including those from the textile industry. Due to the extreme toxicity of aniline, these wastewaters require further treatment. The US Environmental Protection Agency (EPA) has suggested a limit of $262 \mu \mathrm{g} / \mathrm{L}$ of aniline in water, based on health effects [27].

In the present paper, the preparation of Pt catalysts (1\%) supported on CX, MWNT and AC by the method of incipient wetness (IW) is described. Their activities are then determined in the CWAO of aniline. Supports with different textural and surface chemical characteristics were used in order to correlate the support properties with the catalytic activity and selectivity towards $\mathrm{CO}_{2}$ formation.

\section{Experimental}

\subsection{Support preparation}

Three different carbon based supports were used in the preparation of heterogeneous platinum catalysts, namely, MWNT, CX and an AC.

MWNT were prepared by chemical vapor deposition (CVD) of ethylene, using alumina-supported iron as catalyst [28]. The composite material obtained from the CVD production step, consisting of nanotubes, iron and alumina, was then purified by a sulphuric acid treatment. The aim of this step was to accomplish the total dissolution of alumina and the partial elimination of iron contained in the tubes. The final material has a purity of $97 \%$. The nanotubes were further oxidized with $\mathrm{HNO}_{3}(18 \% \mathrm{v} / \mathrm{v})$ for $3 \mathrm{~h}$ in order to create oxygenated functional groups at their surface [10], which will act as anchoring sites for the platinum complexes. Finally, it was washed with water under reflux until neutrality $(\mathrm{pH} \approx 6)$ of the rinsing waters and dried overnight at $110^{\circ} \mathrm{C}$

The CX precursor was synthesized by the conventional sol-gel approach, using formaldehyde and resorcinol (2:1) and aqueous solution of sodium carbonate as catalyst in a ratio 200:60. The solution was mixed uniformly and kept for 1 day at room temperature and the gel was further cured at $50{ }^{\circ} \mathrm{C}$ and $90{ }^{\circ} \mathrm{C}$ for one day at each temperature. The red brown opaque solid gel was then cut, chopped and sectioned into the desired shape and size (around 1-2 $\mathrm{mm}$ ). In order to promote additional cross-linking of the gel, $5 \%$ acetic acid was added to the solvent during the initial water to solvent (acetone) exchange. The excess water was then removed from the gel by several extractions with acetone for $10 \mathrm{~h}$ to obtain acetone filled gel. The acetone filled gel is then further exchanged several times with cyclohexane to remove 
the solvent from the gel for $10 \mathrm{~h}$. Cyclohexane from the pores of the gel is removed slowly by evaporating at ambient temperature and then further by exposing it to hot air at about $50{ }^{\circ} \mathrm{C}$ for $2-3 \mathrm{~h}$. The gel was carbonized at $800{ }^{\circ} \mathrm{C}$ under nitrogen flow of $150 \mathrm{~mL} / \mathrm{min}$ for $6 \mathrm{~h}$, with heating rate of $10{ }^{\circ} \mathrm{C} / \mathrm{min}$. The presence of sodium catalyses the pyrolysis reaction, hence, sodium from the carbonized gel is extracted, using $\mathrm{HCl}$ in a Soxhlet for $6 \mathrm{~h}$, which was subsequently washed with demineralised water several times till $\mathrm{pH} 6-7$, and dried overnight in oven at $110^{\circ} \mathrm{C}$.

The AC used was Norit ROX 0.8 in pellet form $(0.8 \mathrm{~mm}$ diameter, 3-4 mm length), washed with hot hydrochloric acid during $12 \mathrm{~h}$ under reflux in order to remove mineral impurities. Later, it was washed with water under reflux until neutrality $(\mathrm{pH} 6)$ of the rinsing waters and finally dried overnight at $110{ }^{\circ} \mathrm{C}$.

\subsection{Catalyst preparation}

Platinum $(1 \%, w / w ; P t)$ catalysts supported on the different carbon materials were prepared by IW impregnation, using $\mathrm{H}_{2} \mathrm{PtCl}_{6}$ as metal precursor. After impregnation, the catalysts were dried overnight at $110{ }^{\circ} \mathrm{C}$. Prior to reaction the catalysts were heat treated in nitrogen at $400{ }^{\circ} \mathrm{C}$ for $2 \mathrm{~h}$, reduced in hydrogen at $350{ }^{\circ} \mathrm{C}$ for $3 \mathrm{~h}$ and flushed with nitrogen at $350{ }^{\circ} \mathrm{C}$ for $30 \mathrm{~min}$ in order to remove physisorbed hydrogen.

\subsection{Catalyst characterization}

The carbon supports were characterized by temperature programmed desorption (TPD). The samples were placed in a U-shaped quartz reactor and heated up to $1100{ }^{\circ} \mathrm{C}$. $\mathrm{CO}$ and $\mathrm{CO}_{2}$ evolution was recorded using a quadrupole mass spectrometer (Spectramass). The micropore volume $\left(V_{\mu}\right)$ and the non-micropore surface area $\left(S_{\text {non- } \mu}\right)$ were calculated from the $\mathrm{N}_{2}$ adsorption isotherms at $77 \mathrm{~K}$ obtained after outgassing at $350{ }^{\circ} \mathrm{C}$ under vacuum in an automatic analyzer (Coulter Omnisorp $100 \mathrm{CX}$ ) by using the $t$-method. The catalysts metal dispersion was measured by $\mathrm{H}_{2}$ chemisorption at room temperature, using the same equipment. Scanning electron microscopy (SEM) on a JEOL JCM-35C $(15 \mathrm{keV})$ was used for topographical and analytical characterization. Transmission electron microscopy (TEM) observations were performed on a Philips CM12 instrument $(120 \mathrm{keV})$, using carbon-coated copper grids.

\subsection{Oxidation procedure}

The oxidation reactions were performed in a $160 \mathrm{~mL}, 316$ stainless steel high-pressure reactor (model 4564, Parr Instrument Co. Ltd., IL, USA) equipped with a magnetically driven stirrer and a thermocouple. The reactor was heated by an electrical heating mantle controlled by a temperature controller unit (model PID 4842, Parr Instrument).
Typically, in an oxidation run, $75 \mathrm{~mL}$ of the aniline solution $(2 \mathrm{~g} / \mathrm{L})$ and $0.8 \mathrm{~g}$ of catalyst (for CWAO runs) were placed inside the reactor. After 7 min flushing with $\mathrm{N}_{2}$ in order to remove dissolved oxygen, the reactor was heated to the reaction temperature. Once the set temperature was achieved, the first sample was withdrawn, and then the reactor was pressurized with air. At this point the time of reaction was initialized. Periodically, $1 \mathrm{~mL}$ of liquid sample was collected from the reactor to undergo product analysis.

\subsection{Product and data analysis}

Aniline concentration during reaction was determined by injecting samples on a GC chromatograph (DANI GC-1000) equipped with a capillary column (WCOT fused silica $30 \mathrm{~m}$, $0.32 \mathrm{~mm}$ i.d., coated with CP-Sil $8 \mathrm{CB}$ low bleed/MS, $1 \mu \mathrm{m}$ film). The TOC content of the samples was determined in a TOC-analyzer (Shimadzu 5500A). This equipment determines in separate runs the sample total carbon (TC) by combustion at $700{ }^{\circ} \mathrm{C}$ over a Pt catalyst bed and the total inorganic carbon (TIC) by sample treatment with phosphoric acid. TOC is obtained subtracting TIC from TC. For both GC and TOC analysis three reproducible injections (variance less than 2\%) were considered.

With the experimental values of aniline concentration and TOC, it is possible to calculate the reaction selectivity towards $\mathrm{CO}_{2}$ according to a similar protocol previously established for phenol oxidation [29]. The initial TOC concentration $\left([\mathrm{TOC}]_{0}\right)$ and the TOC concentration removed due to aniline oxidation $\left([\mathrm{TOC}]_{\mathrm{A}}\right)$ are given by:

$$
\begin{aligned}
& {[\mathrm{TOC}]_{0}=[\mathrm{A}]_{0} \times\left(\frac{72}{93}\right)} \\
& {[\mathrm{TOC}]_{\mathrm{A}}=\left([\mathrm{A}]_{0}-[\mathrm{A}]\right) \times\left(\frac{72}{93}\right)=X_{\mathrm{A}}[\mathrm{TOC}]_{0}}
\end{aligned}
$$

where $[\mathrm{A}]_{0}$ is the initial aniline concentration, $[\mathrm{A}]$ the aniline concentration at a given time (72/93) the ratio carbon to total mass in the aniline molecule and $X_{\mathrm{A}}$ the aniline conversion.

The difference between the initial and the TOC value at a given time ([TOC]) is attributed to carbon leaving as $\mathrm{CO}_{2}$ :

$[\mathrm{TOC}]_{\mathrm{CO}_{2}}=[\mathrm{TOC}]_{0}-[\mathrm{TOC}]$

Thus, from the definition of selectivity towards $\mathrm{CO}_{2}$ :

$\mathrm{CO}_{2}$ selectivity $=\frac{[\mathrm{TOC}]_{\mathrm{CO}_{2}}}{[\mathrm{TOC}]_{\mathrm{A}}}=\frac{X_{\mathrm{TOC}}}{X_{\mathrm{A}}}$

where $X_{\mathrm{TOC}}$ is the conversion of TOC.

\section{Results and discussion}

\subsection{Catalyst characterization}

The BET surface area, the micropore volume and the surface area determined by the $t$-plot are shown in Table 1 . 
Table 1

Textural characterization of different carbon supports and corresponding platinum catalysts with their metallic dispersions

\begin{tabular}{lcllll}
\hline Material & $\begin{array}{l}S_{\mathrm{BET}} \\
\left(\mathrm{m}^{2} / \mathrm{g}\right)\end{array}$ & $\begin{array}{l}V_{\mu} \\
\left(\mathrm{cm}^{3} / \mathrm{g}\right)^{\mathrm{a}}\end{array}$ & $\begin{array}{l}S_{\text {non- } \mu} \\
\left(\mathrm{m}^{2} / \mathrm{g}\right)^{\mathrm{a}}\end{array}$ & $\begin{array}{l}D_{\mathrm{M}} \\
(\%)\end{array}$ & $d_{\mathrm{P}}(\mathrm{nm})$ \\
\hline MWNT & 175 & 0.001 & 175 & - & - \\
$\mathrm{CX}$ & 724 & 0.110 & 524 & - & - \\
$\mathrm{AC}$ & 1053 & 0.405 & 113 & - & - \\
Pt/MWNT & 169 & 0.001 & 169 & 26.6 & 3.82 \\
Pt/CX & 662 & 0.138 & 325 & 29.2 & 3.48 \\
Pt/AC & 1064 & 0.409 & 125 & 25.0 & 4.06 \\
\hline
\end{tabular}

${ }^{\text {a }}$ Determined by the $t$-plot.

As expected, the support with highest BET surface area is AC $\left(1053 \mathrm{~m}^{2} / \mathrm{g}\right)$. The reason lies essentially on the microporous character of the material with only $10.7 \%$ of the surface area due to non-microporous area. On the other hand, $\mathrm{CX}$ has a large percentage of mesopores contributing to the BET surface area (around $70 \%$ of the $724 \mathrm{~m}^{2} / \mathrm{g}$ ).

The MWNT support has the smallest BET surface area $\left(175 \mathrm{~m}^{2} / \mathrm{g}\right)$. Due to the production mechanism of this material, MWNT are essentially non-porous $\left(S_{\mathrm{BET}}=S_{\mathrm{non}-\mu}\right)$ with all the observed surface area owed to adsorption on the external surface of the tubes [10]. The surface area agrees with the calculated geometric area suggesting that the MWNT have both ends closed and their structure has not been strongly affected by the nitric acid treatment.

The amounts of oxygen containing functional groups were evaluated by TPD and the results obtained are shown in Fig. 1.

It is clear from the profiles obtained that the more oxidized materials correspond to CX and AC. However, MWNT contain oxygenated groups along their surface walls to a non-negligible extent. This is an important observation, because it leads to the conclusion that carbon nanotubes can be non-destructively oxidized along their sidewalls and subsequently, covalently functionalized. It is also worth mentioning that the TPD profiles of MWNT are quite distinct from $\mathrm{AC}$ or $\mathrm{CX}$ suggesting that different types of functional groups are present.

Analysis of Table 2 shows that there are significant differences between the amounts and types of oxygen containing functional groups in the supports. MWNT have

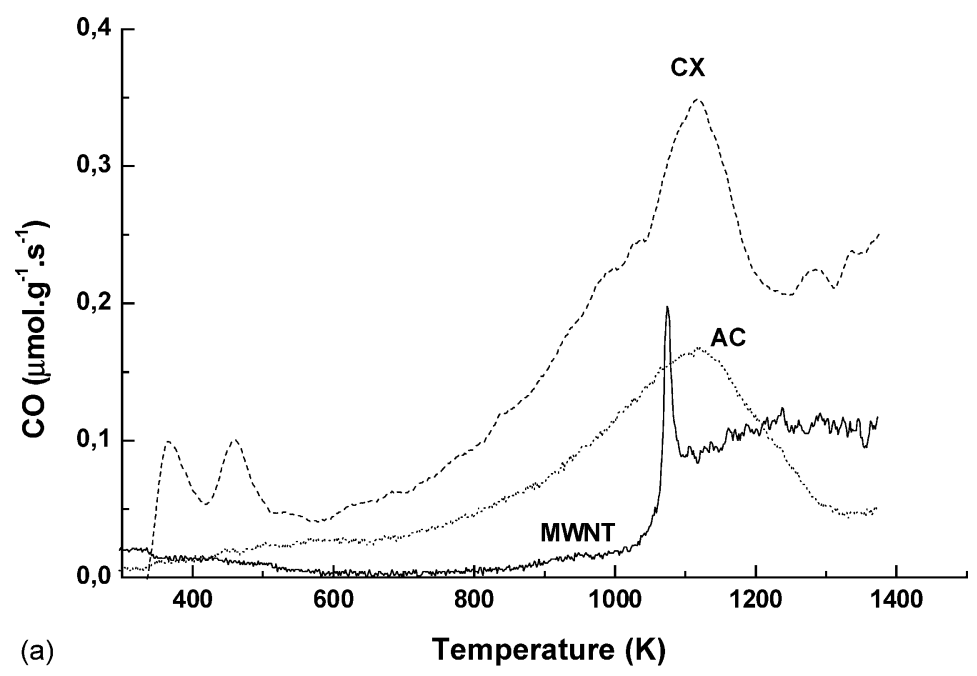

(a)

Temperature (K)

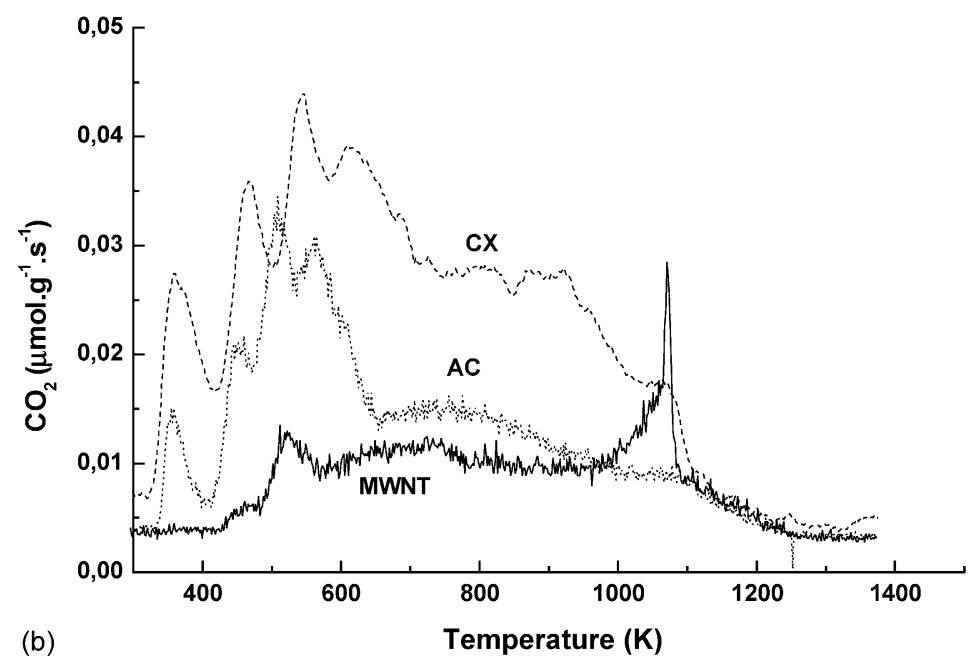

Fig. 1. Profiles of (a) $\mathrm{CO}$ and (b) $\mathrm{CO}_{2}$ evolution during the TPD of different carbon materials. 
Table 2

Total amounts of $\mathrm{CO}$ and $\mathrm{CO}_{2}$ released by TPD during chemical characterization of the different carbon materials

\begin{tabular}{lcclc}
\hline Support & $\mathrm{CO}(\mu \mathrm{mol} / \mathrm{g})$ & $\mathrm{CO}_{2}(\mu \mathrm{mol} / \mathrm{g})$ & $\mathrm{CO} / \mathrm{CO}_{2}$ & Total $\mathrm{O}_{2}(\mu \mathrm{mol} / \mathrm{g})$ \\
\hline MWNT & 26 & 59 & 0.44 & 72 \\
$\mathrm{CX}$ & 709 & 217 & 3.27 & 572 \\
$\mathrm{AC}$ & 472 & 106 & 4.45 & 342 \\
\hline
\end{tabular}

lower concentration of oxygen containing functional groups $\left(72 \mu \mathrm{mol}_{\mathrm{O}_{2}} / \mathrm{g}\right.$ ), $\mathrm{CO}_{2}$ evolving oxygen groups predominating. $\mathrm{CX}$ and $\mathrm{AC}$ have larger amounts, respectively, 572 and $342 \mu \mathrm{mol}_{\mathrm{O}_{2}} / \mathrm{g}$, CO evolving oxygen groups predominating. Due to the amount of oxygen present at their surfaces, CX and $\mathrm{AC}$ are expected to exhibit stronger acidic character.

Impregnation with Pt leads to very similar metal dispersions in all the materials ( $D_{\mathrm{M}}$ ranging from 25 to $29 \%$ ) and consequently, the calculated diameter $\left(d_{\mathrm{P}}\right)$ of the Pt crystallites (assuming spherical geometry) is also similar (Table 1).

On the other hand, there were no drastic changes in the surface area of the resulting catalysts. In the case of CX, there is an increase on the reported $V_{\mu}$ that is produced at the expense of the mesoporous structure.

In most cases, the introduction of platinum can lead to catalytic gasification of the carbon material during the $\mathrm{H}_{2}$ reduction step and is responsible for the increase in BET surface area of the AC based catalyst, although in this case, the increase in the micropore volume is more modest. Further support for the occurrence of gasification comes from the observation that methane was released during the reduction process in the preparation of the catalyst.

For MWNT the differences are too small to be significant. Some area is lost due to the introduction of platinum onto the surface, however that can be calculated to be not greater than $0.8 \mathrm{~m}^{2} / \mathrm{g}$ (corresponding to the available metal surface area).

The good metal dispersion of all prepared catalysts was confirmed by the SEM/EDS and TEM analyses. SEM and TEM micrographs show that the platinum particles are very well distributed over the carbonaceous supports. The calculated average size of the particles was between 3.5 and $4.1 \mathrm{~nm}$ (Table 1), based on the measured dispersions. For Pt/ CX and Pt/AC, Pt particles homogeneously distributed could be observed at lower magnifications. For Pt/MWNT, due to the fluffy nature of the material with a tendency to aggregate, higher magnifications were required to observe the Pt crystallites, which were masked by the material arrangement. The platinum particles on Pt/MWNT are clearly visible on SEM (Fig. 2a) and TEM (Fig. 2b) micrographs. The presence of Pt on the catalyst was confirmed by EDS analysis all over the sample.

\subsection{Oxidation reactions}

The prepared catalysts were tested in the CWAO of aniline at $200{ }^{\circ} \mathrm{C}$ and 6.9 bar of oxygen partial pressure. The results obtained are given in Fig. 3, where a run without catalyst is also shown for comparison purposes.

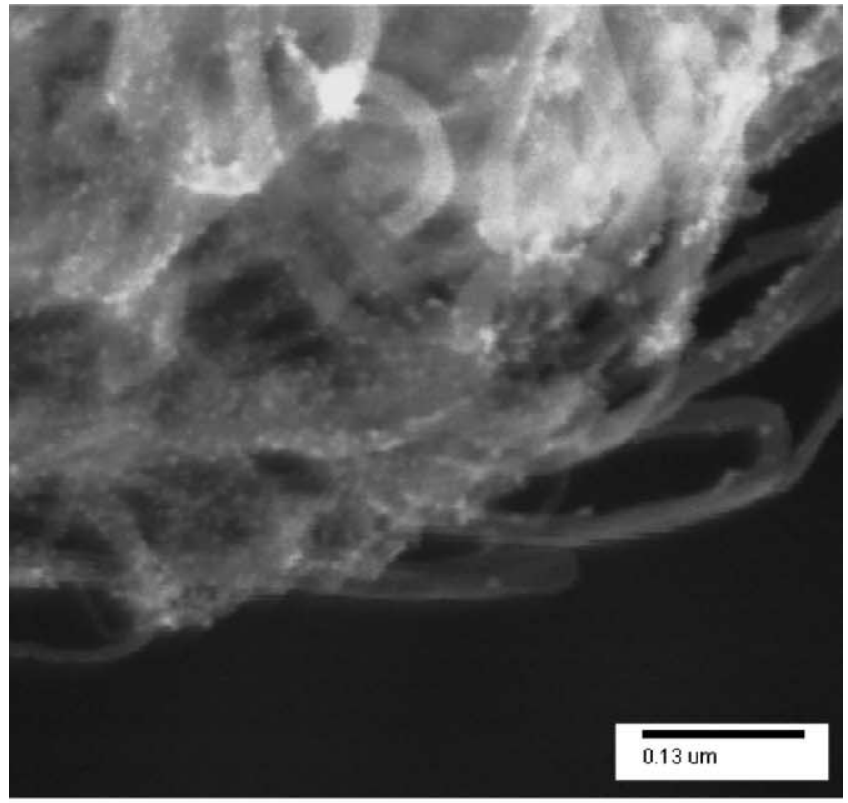

(a)

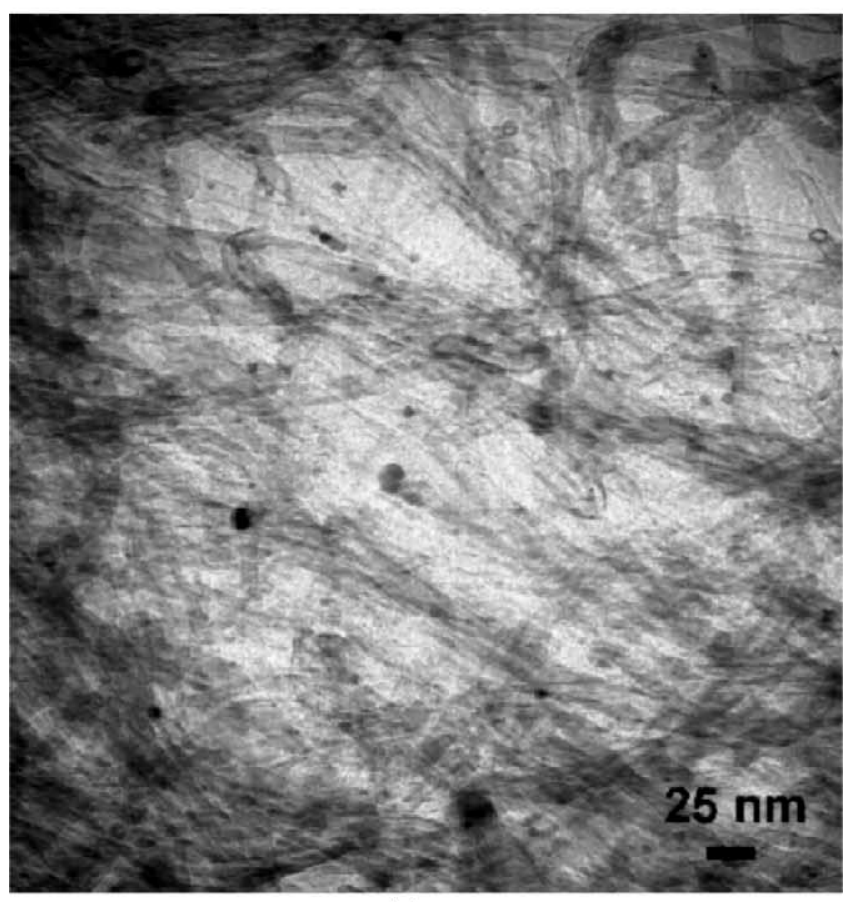

(b)

Fig. 2. Micrographs of the Pt/MWNT catalyst by (a) SEM and (b) TEM.

It can be observed from Fig. 3 that the oxidation of aniline occurs to some extent in the absence of catalyst, with $45.1 \%$ conversion after $2 \mathrm{~h}$ of reaction and $60.8 \%$ selectivity towards $\mathrm{CO}_{2}$ formation. Observation of an increasingly intense orange color during the progression of the reaction suggested the formation of intermediate azoic compounds [22] accounting for the low selectivity of the non-catalytic WAO.

The observed conversion can be interpreted in terms of a pseudo first order kinetic scheme, were the rate is directly 


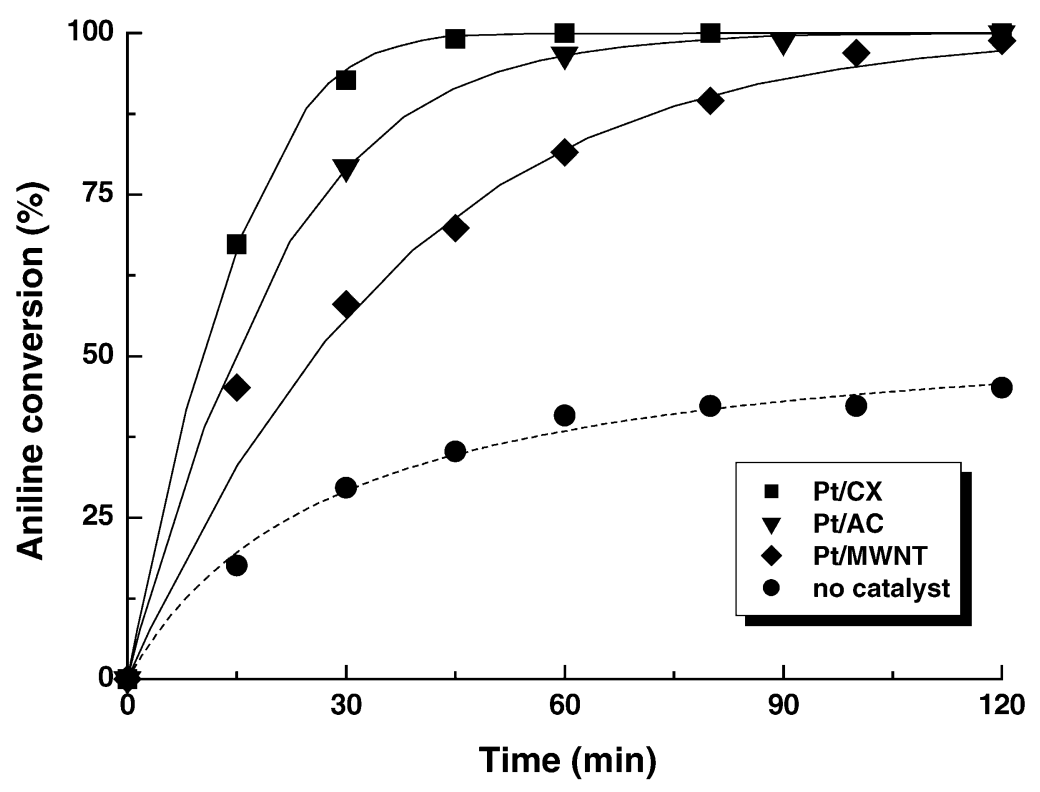

Fig. 3. Aniline conversion in the catalytic and non-catalytic WAO of aqueous solutions.

proportional to the catalyst coverage by the organic substrate (except in the case of non-catalytic WAO). The initial step corresponds to adsorption of aniline, followed by oxidation of the organic molecule, desorption of the oxidized radical and oxygen mediated degradation in solution [30]. Under these conditions, Langmuir-Hinshelwood type kinetics can be assumed:

$r=\frac{(1 / W) k K[\mathrm{~A}]}{(1+K[\mathrm{~A}])}$

where $W$ is the active phase concentration $\left(\mathrm{g}_{\mathrm{P}} / \mathrm{L}\right), k$ the kinetic rate constant, $K$ the aniline adsorption equilibrium constant and $[\mathrm{A}]$ the aniline concentration. The results of the fit are expressed in terms of the lines drawn in Fig. 3 (except for the non-catalytic case) and the corresponding values of $k$ and $K$ are given in Table 3. The initial rate $\left(r_{0}\right.$, Table 3$)$ is defined as the specific reaction rate per gram of metal when the reaction time is close to zero, which is when the concentration of aniline approaches its initial value. The initial rate $\left(r_{0}\right)$ values were calculated fitting the kinetic model to all the experimental points. Analyzing the data, we can conclude that the initial reaction rates $\left(r=r_{0}\right.$ for $\left.t=0\right)$ decrease in the order Pt/CX $>\mathrm{Pt} / \mathrm{AC}>\mathrm{Pt} / \mathrm{MWNT}$. As the reaction proceeds (higher aniline conversion), the rates of reaction $(r)$ obtained for each catalytic system decrease with the decreasing of aniline concentration in solution. From 0 to $100 \%$ of aniline conversion, the measured reaction rates follow the same order as obtained for the initial reaction rates.

It is worth mentioning that the kinetic rate constant is higher in the case of Pt/MWNT, while the equilibrium constant for adsorption is very low, resulting in a low overall initial rate. For the other catalysts the effect is quite the opposite. Thus, due to a more regular structure, MWNT will allow to produce well-dispersed catalysts at higher metal loads, making it possible to take advantage of the observed high reaction rates reported here.

It is clear that the introduction of the catalyst led to an almost complete conversion of aniline in the three cases: comparing the conversion after $2 \mathrm{~h}$ of reaction $\left(X_{2} \mathrm{~h}\right.$, Table 3$)$ for all catalysts we can observe that almost no difference exists between them. After $2 \mathrm{~h}$ of reaction $100 \%$ conversion of aniline was obtained with $\mathrm{Pt} / \mathrm{CX}$ and $\mathrm{Pt} / \mathrm{AC}$ catalysts, and $98.8 \%$ conversion with the Pt/MWNT catalyst. Trying to correlate the observed catalyst activities with the textural and chemical characteristics of the respective supports (Tables 1 and 2), it is clear that the activity is favoured by the mesoporous character of the support and by the concentration of oxygen bearing functional groups present on its surface. These characteristics facilitate aniline adsorption on the support surface for subsequent reaction at the

Table 3

Reaction data for the CWAO of aniline, using platinum supported on different carbon materials at $200{ }^{\circ} \mathrm{C}$ and 6.9 bar of oxygen partial pressure

\begin{tabular}{llllcl}
\hline Catalyst & $r_{0}\left(10^{-3} \mathrm{~mol} \mathrm{~min}^{-1} \mathrm{~g}_{\mathrm{Pt}}{ }^{-1}\right)$ & $k\left(10^{-3} \mathrm{~mol} \mathrm{~L}^{-1} \mathrm{~min}^{-1}\right)$ & $K\left(\mathrm{~L} \mathrm{~mol}^{-1}\right)$ & $X_{2 \mathrm{~h}}(\%)$ & $\mathrm{CO}_{2}$ selectivity $(2 \mathrm{~h}, \%)$ \\
\hline Pt/MWNT & 5.0 & 2.37 & 13.4 & 98.8 & 86.9 \\
Pt/CX & 8.5 & 1.42 & 82.9 & 100 & 92.7 \\
Pt/AC & 7.1 & 1.75 & 35.0 & 100 & 94.5 \\
No catalyst & - & - & - & 45.1 & 60.8 \\
\hline
\end{tabular}




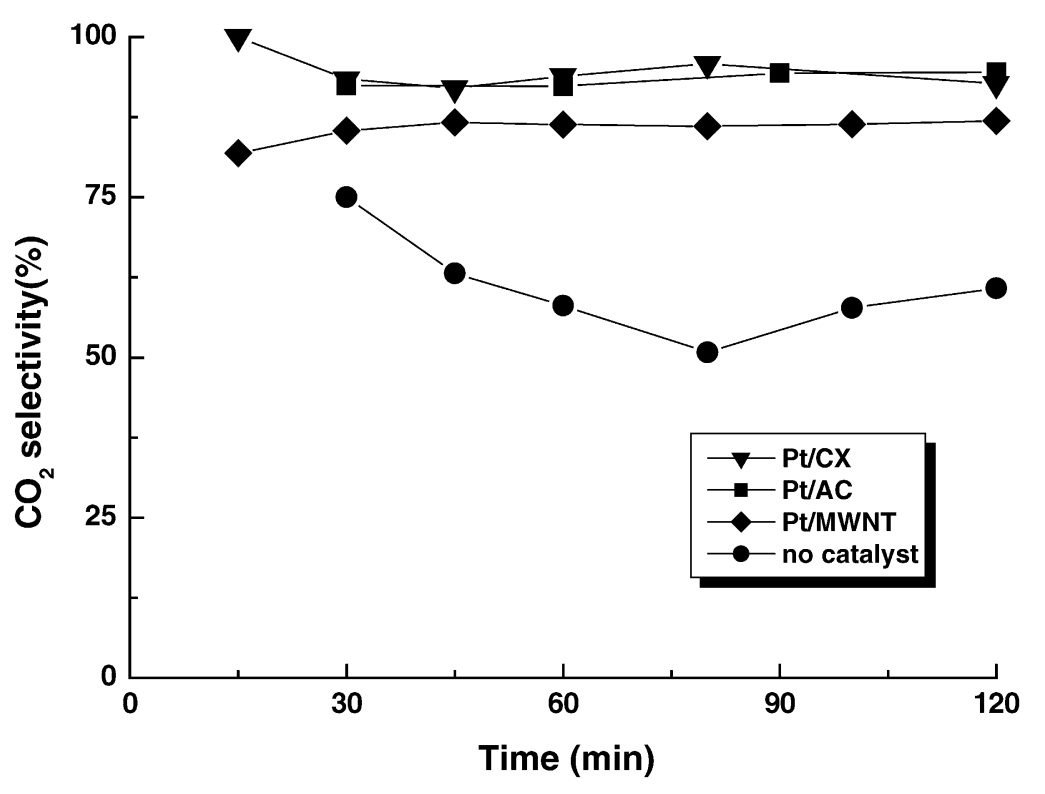

Fig. 4. Selectivity towards $\mathrm{CO}_{2}$ formation in the catalytic wet air oxidation of aniline, using platinum supported on different carbon materials.

metal active sites. Higher mesoporous area allows easier diffusion of reactants than in microporous environments. Due to resonance effects [31], aniline develops a significant basicity, favoring adsorption on acid supports.

The calculated selectivity to $\mathrm{CO}_{2}$ (Table 3 ) follows the aniline conversion, with the selectivity values increasing in the same order. For each catalyst, the selectivity is practically constant in time, which is another advantage of CWAO when compared to WAO (Fig. 4).

Simultaneous analysis of Figs. 3 and 4 leads to the conclusion that $\mathrm{Pt} / \mathrm{CX}$ and $\mathrm{Pt} / \mathrm{AC}$ catalysts are very active and selective (selectivity of around $95 \%$ after $2 \mathrm{~h}$ of reaction). No coloration was developed during the course of the reaction. Nevertheless Pt/MWNT is also very active, its performance is slightly inferior, only $98.8 \%$ conversion being registered. During the catalytic experiment with Pt/ MWNT, a faint orange color developed as the reaction proceeded (selectivity of $87 \%$ after $2 \mathrm{~h}$ of reaction), indicating the occurrence of some stable intermediates. The CWAO of aniline is known to lead to the formation of some azo compounds (hydrazobenzene, azobenzene and azoxybenzene), nitrogenous aromatic compounds ( $p$-aminophenol, nitrobenzene, $p$-nitrophenol and nitrosobenzene) and other aromatics (phenol, hydroquinone, catechol and benzoquinone) [32]. However, due to their mechanical strength the carbon MWNT are expected to be very resistant in longer cycles of catalyst re-use.

\section{Conclusion}

Pt catalysts supported on different carbon materials by IW impregnation showed a very high efficiency for the CWAO of aniline. Practically complete removal of aniline was obtained at $200{ }^{\circ} \mathrm{C}$ with all the catalysts after $2 \mathrm{~h}$ of reaction. Although, all catalysts are very active, they presented different selectivity toward $\mathrm{CO}_{2}$ formation, $\mathrm{Pt} / \mathrm{CX}$ and Pt/AC being more selective than the Pt/MWNT catalyst. Nevertheless, this work represents one of the first applications of MWNT in environmental protection. Additionally, the results obtained suggest that better supported-catalysts can be produced at higher metal loading. Indeed, high loading and well-dispersed nanotube-supported catalysts have been already recently reported [14].

A global analysis of the results based on the comparison of initial rates leads to the conclusion that the activity and the selectivity to $\mathrm{CO}_{2}$ of the $\mathrm{Pt}$ supported catalysts increases with the mesoporous character of the materials and with the concentration of oxygen containing functional groups on the surface of the support.

Environmental protection is a great challenge to be faced by industry, since the environmental regulations will certainly impose more stringent limits in the future, which will may justify the use of more sophisticated catalysts. The results obtained confirm the potentialities of these new carbon materials as supports for the development of highly active heterogeneous catalysts.

\section{Acknowledgment}

This work was supported by Fundação para a Ciência e a Tecnologia, POCTI and FEDER (Projects POCTI/EQU/ $33401 / 2000$ and POCTI/118/2003) and by CRUP (F-12/03).

\section{References}

[1] H.W. Kroto, J.R. Heath, S.C. Obrien, R.F. Curl, R.E. Smalley, Nature 318 (1985) 162. 
[2] H.W. Kroto, Nature 329 (1987) 529.

[3] S. Iijima, Nature 354 (1991) 56.

[4] S. Iijima, T. Ichihashi, Y. Ando, Nature 356 (1992) 776.

[5] S. Iijima, T. Ichihashi, Nature 363 (1993) 603.

[6] M. Terrones, N. Grobert, J. Olivares, J.P. Zhang, H. Terrones, K. Kordatos, W.K. Hsu, J.P. Hare, P.D. Townsend, K. Prassides, A.K. Cheetham, H.W. Kroto, D.R.M. Walton, Nature 388 (1997) 52.

[7] S. Iijima, Physica B 323 (2002) 1.

[8] C.N.R. Rao, B.C. Satishkumar, A. Govindaraj, M. Nath, Chem. Phys. Chem. 2 (2001) 78.

[9] B. Rajesh, K.R. Thampi, J.M. Bonard, N. Xanthopoulos, H.J. Mathieu, B. Viswanathan, J. Phys. Chem. B 107 (2003) 2701.

[10] R. Giordano, P. Serp, P. Kalck, Y. Kihn, J. Schreiber, C. Marhic, J.-L. Duvail, Eur. J. Inorg. Chem. (2003) 610.

[11] K. Hernadi, L. Thien-Nga, E. Ljubovic, L. Forro, Chem. Phys. Lett. 367 (2003) 475

[12] J.P. Tessonnier, L. Pesant, C. Pham-Huu, G. Ehret, M.J. Ledoux, Scientific Bases for the Preparation of Heterogeneous Catalysts, vol. 143, 2002, p. 697.

[13] J.M. Nhut, R. Vieira, L. Pesant, J.P. Tessonnier, N. Keller, G. Ehret, C. Pham-Huu, M.J. Ledoux, Catal. Today 76 (2002) 11.

[14] P. Serp, M. Corrias, P. Kalck, Appl. Catal. A 253 (2003) 337.

[15] R.W. Pekala, J. Mater. Sci. 24 (1989) 3221.

[16] E.J. Zanto, S.A. Al-Muhtaseb, J.A. Ritter, Ind. Eng. Chem. Res. 41 (2002) 3151.
[17] A.T. Bell, Science 299 (2003) 1688.

[18] G. Chen, L. Lei, P.-L. Yue, Ind. Eng. Chem. Res. 38 (1999) 1837.

[19] L. Lei, G. Chen, X. Hu, P.-L. Yue, Water Environ. Res. 72 (2000) 147.

[20] X. Hu, L. Lei, G. Chen, P.L. Yue, Water Res. 35 (2001) 2078.

[21] L. Oliviero, J. Barbier Jr., D. Duprez, A. Guerrero-Ruiz, B. BachillerBaeza, I. Rodríguez-Ramos, Appl. Catal. B 25 (2000) 267.

[22] L. Oliviero, J. Barbier Jr., D. Duprez, Appl. Catal. B 40 (2003) 163.

[23] H.T. Gomes, J.L. Figueiredo, J.L. Faria, Catal. Today 75 (2002) 23.

[24] H.T. Gomes, J.L. Figueiredo, J.L. Faria, Appl. Catal. B 27 (2000) 217.

[25] S.H. Gheewala, A.P. Annachhatre, Water Sci. Technol. 36 (1997) 53.

[26] Petrochemicals Manufacturing, Pollution Prevention and Abatement Handbook, World Bank Group, July 1998, pp. 371.

[27] J. Sarasa, S. Cortés, P. Ormad, R. Garcia, J.L. Ovelleiro, Water Res. 36 (2002) 3035 .

[28] M. Corrias, B. Caussat, A. Ayral, J. Durand, Y. Kihn, P. Kalck, P. Serp, Chem. Eng. Sci. 58 (2003) 4475.

[29] S.S. Lin, C.L. Chen, D.J. Chang, C.C. Chen, Water Res. 36 (2002) 3009 .

[30] H.T. Gomes, J.L. Figueiredo, J.L. Faria, P. Serp, P. Kalck, J. Mol. Catal. A 182-183 (2002) 48.

[31] M.B. Smith, J. March, March's Advanced Organic Chemistry. Reactions, Mechanisms, and Structure, Wiley, New York, 2001.

[32] L. Oliviero, H. Wahyu, J. Barbier Jr., D. Duprez, J.W. Ponton, D. Metcalfe, D. Mantazavinos, Trans. Inst. Chem. Eng. 81 (2003) 384. 